\title{
CRESCIMENTO DE ÓRGÃOS DO APARELHO REPRODUTOR DURANTE O DESENVOLVIMENTO DE Biomphalaria tenagophila (ORBIGNY) (MOLLUSCA, PLANORBIDAE)
}

\author{
MONTEIRO, W. ${ }^{1}$ e KAWANO, T. ${ }^{2}$ \\ ${ }^{1}$ Departamento de Ecologia, Universidade de Brasília, Brasília, DF \\ ${ }^{2}$ Laboratório de Biologia Celular, Instituto Butantan, Av. Vital Brasil, 1500, CEP 05503-900, São Paulo, SP \\ Correspondência para: Toshie Kawano, Laboratório de Biologia Celular, Instituto Butantan, \\ Av. Vital Brasil, 1500, CEP 05503-900, São Paulo, SP, Brasil \\ Recebido em 10/07/97 - Aceito em 05/06/98 - Distribuído em 30/11/98
}

(Com 5 figuras)

\begin{abstract}
Growth of reproductive system organs during the development of Biomphalaria tenagophila (Orbigny) (Mollusca, Planorbidae)
\end{abstract}

\begin{abstract}
Biomphalaria tenagophila is a simultaneous hermaphrodite whose's male function was evaluated by the growth of the sex organs in relation to the shell diameter. New techniques were applied to measure reproductive organs without apparent distorsion and to count individual ovotestis follicles. During the growth of sexually mature specimens of $B$. tenagophila the ovotestis follicles increased in number, but the maximum and minimum values are smaller than the ones found in the literature. The number of $B$. glabrata prostate diverticula and ovotestis follicles were greater than that of $B$. tenagophila. Although the length of ovotestis, prostate, penial sheath and muciparous-oothecal gland varied during B. tenagophila's growth, the number of prostate diverticula remained signifcantly stable.
\end{abstract}

Key words: Biomphalaria tenagophila, growth, reprodutive system.

\section{RESUMO}

Biomphalaria tenagophila é um hermafrodita simultâneo cujo investimento na função masculina foi avaliado pelo crescimento de seus órgãos sexuais em relação ao diâmetro da concha. Foram criadas novas técnicas para medir órgãos reprodutivos, sem aparentes distorções, e contar folículos do ovoteste. Durante o crescimento de espécimes sexualmente maduros de $B$. tenagophila, cresceu o número de folículos do ovoteste, mas seus números máximos e mínimos são menores do que os citados na literatura. O número de divertículos da próstata e de folículos do ovoteste de B. glabrata é maior do que o de B. tenagophila. Embora o comprimento do ovoteste, da próstata, da bainha do pênis e da glândula mucípara-ootecal variassem durante o crescimento do caramujo, não variou significativamente o número de divertículos da próstata.

Palavras-chave: Biomphalaria tenagophila, crescimento, aparelho reprodutor.

\section{INTRODUÇÃO}

Os caracteres sexuais primários são os órgãos de reprodução, enquanto os secundários referemse às características que, embora indiretamente ligadas aos órgãos repr odutivos, podem auxiliar na distinção entre machos e fêmeas. A seleção natural é um processo que premia os indivíduos que deixam maior número de descendentes para as gerações subseqüentes, isto é, têm maior sucesso reprodutivo, em detrimento daqueles indivíduos que são menos fecundos. Machos e fêmeas 
dependem de diferentes estratégias sexuais, que são apropriadas a cada sexo, para uma reprodução bem-sucedida (Halliday, 1980).

Geralmente, o investimento inicial feito pelo macho na reprodução, como acontece no momento da fertilização, é menor que o feito pela fêmea. Mas existe uma evolução social ajustando os aspectos comportamentais que aumentam o sucesso reprodutivo dos parceiros (Trivers, 1985).

Dentro de uma perspectiva evolutiva, a comparação entre gonocoristas e hermafroditas simultâneos inclui um padrão de energia alocada para tecidos somáticos em geral e para os envolvidos na reprodução (Fisher, 1958; Heller, 1990). O desvio do equilíbrio, favorecendo as funções reprodutivas, pode levar a uma diminuição da longevidade do indivíduo (Sohn \& Policansky, 1977). É possível que haja uma alternância para investimento nas ações reprodutivas e na manutenção das funções somáticas (Pianka \& Parker, 1975). Particularizando, mesmo dentro do aparelho reprodutor, há dois grupos de investimentos indispensáveis. Um inclui a produção e a manutenção do aparelho reprodutor: órgãos copuladores, gônadas, dutos associados e produção de gametas (Heath, 1977). Ora, o investimento de um gonocorista no aparelho reprodutor é aproximadamente a metade daquele de um hermafrodita simultâneo. Mesmo com a vantagem que o hermafrodita possui, por ter a parte hermafrodita do aparelho reprodutor comum aos dois sexos, o modelo gonocorista ainda é mais econômico. Além disso, cada indivíduo gonocorista investe na produção de apenas um tipo de gameta. Conseqüentemente, num balanço final, dois hermafroditas simultâneos têm menos energia disponível para aplicar na produção de gametas do que dois indivíduos de uma espécie gonocorista (Heath, 1977).

Um estudo da variação contínua e merística de diferentes órgãos do aparelho reprodutor de caramujos sexualmente maduros tem particular importância para identificar os órgãos que concorrem em investimento na produção de gametas. A bionfalária possui o ovoteste na extremidade do aparelho reprodutor, no qual produz óvulos e espermatozóides simultaneamente (Barth \& Jansen, 1959). Em continuidade com o ovoteste está a vesícula seminal. Em seguida, no carrefour, os órgãos masculinos e femininos separam-se até as respectivas aberturas para o exterior, no lado esquerdo da extremidade cefálica. A espermateca é um órgão piriforme, de fundo cego, que se abre na vagina por um curto canal (Paraense, 1975).

No estudo do investimento reprodutivo de B. tenagophila, é importante que se contabilizem as alocações de recursos feitas nos órgãos reprodutivos sob a forma de crescimento de órgãos.

Diferentes tipos de investimentos podem influir na alocação de recursos para o desenvolvimento do aparelho reprodutor de B. tenagophila, durante o crescimento do indivíduo sexualmente maduro. A alocação desses recursos será investigada pela observação das alterações morfológicas ocorridas nas gônadas e dutos do aparelho reprodutor.

\section{MATERIAIS E MÉTODOS}

Os caramujos usados nos experimentos foram B. tenagophila, tipo selvagem e mutantes albinos, procedentes de Bom Retiro, em Joinville, $\mathrm{SC}$, mantidos agrupados, durante mais de quatro anos, em condições de laboratório. Os aquários foram preparados com $180 \mathrm{ml}$ de água filtrada, saturada com carbonato de cálcio. Em cada aquário foi colocada uma colher de sopa de terra avermelhada, esterilizada em estufa seca a $90^{\circ} \mathrm{C}$ durante 12 horas. Os caramujos foram alimentados ad $l i$ bitum com alface fresca e ração duas vezes por semana. Para fazer uma comparação com $B$. tenagophila, foram usados exemplares, de campo, de B. glabrata, de 12 ou $14 \mathrm{~mm}$ de diâmetro, coletados em Moreira Sales, PR, e mantidos em condições de laboratório.

As análises estatísticas foram feitas pelo programa produto SPSS (Statistical Package for Social Sciences) (Nie et al, 1975), sobre dados importados do dBase IV - Ashton-Tate Corporation, 1988.

Para dissecação, a concha foi quebrada por compressão entre duas lâminas, sem rotura dos órgãos. Com auxílio de duas pinças, foram dissecados sob microscópio estereoscópico 113 exemplares de B. tenagophila, de 4 a $12 \mathrm{~mm}$ de diâmetro, e B. glabrata, de 12 ou 14 mm.

Os órgãos eram dissecados em uma solução de sacarose a $50 \%$ para minimizar o relaxamento ou contração durante o preparo e medição. Os comprimentos foram medidos com uma ocular micrométrica.

As medidas dos ovotestes foram feitas juntamente com a cauda, isto é, uma câmara na parte final do corpo do caramujo, sem folículos, mas 
com diversas vesículas claras de tamanho variado. A glândula mucípara e a glândula ootecal foram medidas em conjunto. Este conjunto é denominado de glândula nidamental por Paraense (1975). Ainda em solução de sacarose a $50 \%$, foram separados, ovoteste com a cauda do ovoteste, próstata, glândula mucíparaootecal e a bainha do pênis (Tomé, 1995).

O comprimento da bainha do pênis foi tomado entre os limites com o prepúcio e com o canal deferente. A medida da próstata foi tomada desde o lado externo do pedúnculo do primeiro divertículo até o lado externo do último pedúnculo. Não foi medida a largura da próstata. O ovoteste foi medido do contorno anterior da massa folicular até o final da cauda do ovoteste. A cauda do ovoteste foi incluída, pois este é o modo tradicional de medir ovoteste (Paraense, 1975). Porém, neste trabalho, o tamanho da cauda do ovoteste também foi medido, uma vez que sua variação parecia significativa. O comprimento da cauda do ovoteste foi considerado desde o contorno do último folículo do ovoteste até o final do corpo do animal. Após a medida do comprimento da próstata, teve início seu preparo para a contagem dos divertículos. Fixados em solução de Railliet-Henry (água destilada $930 \mathrm{ml}, \mathrm{NaCl} 6 \mathrm{~g}$, formol $50 \mathrm{ml} \mathrm{e}$ ácido acético $20 \mathrm{ml}$ ), por duas horas no mínimo, os pedúnculos dos divertículos eram separados com dois estiletes de dissecação e contados.

Para a contagem dos folículos, o ovoteste era fixado, por duas horas, em solução de RaillietHenry saturada com cloreto de sódio. Em seguida, era transferido para ácido nítrico $40 \%$, por 90 minutos, e, novamente, fixado, por no mínimo duas horas, em solução de Railliet-Henry saturada com cloreto de sódio. Com o auxílio de dois estiletes de dissecação, os folículos eram individualizados e contadas as ramificações. Tanto os divertículos da próstata como os folículos do ovoteste foram contados sob microscópio estereoscópico, com aumento de 40 vezes.

\section{RESULTADOS E DISCUSSÃO}

Foram feitas estatísticas das medidas de vários órgãos do aparelho reprodutor de $B$. tenagophila. Foi testada a homoscedasticidade das medidas (Tabela 1), como suporte na decisão para a aplicação de análise paramétrica, ou nãoparamétrica.

Os comprimentos da cauda do ovoteste, do ovoteste, da glândula mucípara-ootecal, da próstata e da bainha do pênis e o número de divertículos da próstata podem ter um tratamento estatístico paramétrico, porque o valor de $\mathrm{P}$ é maior que $5 \%$. Porém, o valor referente ao número de folículos do ovoteste ficou aquém do limite tolerável (5\%) para execução de testes paramétricos (Tabela 1). Como o teste de BartlettBox tem sensibilidade a populações afastadas da normalidade, a distribuição do número de folículos do ovoteste pode não ser normal. Mas é possível aumentar a homoscedasticidade de algumas variáveis por meio de sua transformação em LN (variável + 1) (Zar, 1974). De fato, após a transformação, os testes de homoscedasticidade do número de folículos do ovoteste passaram a ter os seguintes valores: Cochrans $\mathrm{C}=0,24, \mathrm{P}=$ 0,05 ; Bartlett-Box $\mathrm{F}=1,42, \mathrm{P}=0,18$; variância máxima/variância mínima $=7,88$. Portanto, a aná-

TABELA 1

Teste F de Bartlett-Box para a homoscedasticidade das medidas dos órgãos de B. tenagophila durante o crescimento de 4 a 12 mm de diâmetro da concha. $H_{0}$ : variâncias são homogêneas.

\begin{tabular}{|l|c|c|}
\hline \multirow{2}{*}{ Característica } & \multicolumn{2}{c|}{ Teste F de Bartlett-Box } \\
\cline { 2 - 3 } & F & P \\
\hline Comprimento da cauda do ovoteste & 1,29 & 0,25 \\
\hline Comprimento do ovoteste & 1,16 & 0,32 \\
\hline Número de folículos do ovoteste & 3,71 & 0,00 \\
\hline Comprimento da glândula mucípara-ootecal & 1,33 & 0,22 \\
\hline Comprimento da próstata & 1,39 & 0,20 \\
\hline Número de divertículos da próstata & 0,61 & 0,77 \\
\hline Comprimento da bainha do pênis & 0,25 & 0,97 \\
\hline
\end{tabular}


lise do número de folículos do ovoteste foi realizada sobre seus números transformados.

O número de folículos do ovoteste de $B$. tenagophila difere significativamente em indivíduos de 4 a 12 mm de diâmetro de concha (Tabela 3). A aplicação de um teste de comparações múltiplas (Student-Newman-Keuls) (Fig. 1) mostra que não há diferença significativa em nível de $50 \%$ entre os números de folículos do ovoteste em caramujos de 4 a 6 mm de diâmetro. Quanto aos demais tamanhos, há uma aparente incoerência. Enquanto o número de folículos do ovoteste de caramujos de $12 \mathrm{~mm}$ de diâmetro difere significativamente do de caramujos de 10 e $11 \mathrm{~mm}$ de diâmetro, não difere do número de folículos do ovoteste de caramujos de $8 \mathrm{~mm}$ de diâmetro. Essa incoerência pode-se dever ao maior número de caramujos (75) com diâmetro a partir de $10 \mathrm{~mm}$, sendo que foram utilizados apenas cinco caramujos de $8 \mathrm{~mm}$. De qualquer forma, essa representação (Fig. 1) sugere uma ocorrência de significativa alteração no número de folículos quando o caramujo atinge 6 ou $7 \mathrm{~mm}$ de diâmetro. Como B. tenagophila amplia o número de folículos durante o crescimento (Tabela 3), esse é um investimento que tem significado para a reprodução, uma vez que cada folículo representa uma unidade de produção de gametas masculinos e femininos. Esse aumento deve influir no aumento do diâmetro ou do comprimento do ovoteste (Fig. 3, Tabelas 8 e 9). O diâmetro do ovoteste não foi medido neste trabalho.

Os números de folículos do ovoteste e de divertículos da próstata são considerados para iden- tificação de espécies de planorbídeos. Segundo a literatura, os valores máximos e mínimos para B. tenagophila são 150 e 350 folículos e 8 e 30 divertículos (Paraense, 1975).

Em relação aos dados publicados, os da Tabela 2 são valores discrepantes: entre 82 e 302 folículos. Essa discrepância permanece, mesmo selecionando apenas os dados dos exemplares de 12 mm de diâmetro (125 a 302), os maiores diâmetros dentre os usados para as contagens neste trabalho. É possível que essas variações se devam à diferença de origem das populações, ou ocorram entre populações naturais e de laboratório. De qualquer forma, no uso dessa característica, é preciso atentar para o tamanho do animal examinado, pois o número de folículos do ovoteste varia, significativamente, durante o crescimento do animal (Fig. 1, Tabela 3).

As médias, modas, valores máximos e mínimos do número de folículos do ovoteste mostram diferenças entre $B$. tenagophila e B. glabrata, sem interseção, uma vez que o valor máximo, 302, de B. tenagophila (Tabela 2) é menor que o valor mínimo, 350, de B. glabrata, segundo Paraense (1975). Há, porém, uma discrepância, o número mínimo de folículos de ovotestes de espécimes de $12 \mathrm{~mm}$ de diâmetro, de B. glabrata, eram 278 (Tabela 4). Como havia homoscedasticidade (Bartlett-Box $\mathrm{F}=0,677, \mathrm{P}=0,411$ ), foi feita análise de variância entre o número de folículos das duas espécies: $\mathrm{F}=137,87 ; \mathrm{P}=0,00$. Realmente, para essas duas espécies, os resultados mostram que o número de folículos do ovoteste é um bom caráter diagnóstico. $\mathrm{O}$ número médio,

TABELA 2

Parâmetros estatísticos do número de folículos do ovoteste de diferentes tamanhos de B. tenagophila.

\begin{tabular}{|c|c|c|c|c|c|}
\hline Diâmetro & Média & Moda & Mín. & Máx. & n \\
\hline $\mathbf{0 4}$ & 104 & 82 & 82 & 131 & 06 \\
\hline $\mathbf{0 5}$ & 98 & 85 & 85 & 110 & 06 \\
\hline $\mathbf{0 6}$ & 108 & 120 & 97 & 120 & 06 \\
\hline $\mathbf{0 7}$ & 138 & 116 & 116 & 194 & 06 \\
\hline $\mathbf{0 8}$ & 148 & 121 & 121 & 167 & 05 \\
\hline $\mathbf{0 9}$ & 146 & 118 & 116 & 183 & 09 \\
\hline $\mathbf{1 0}$ & 150 & 130 & 113 & 228 & 23 \\
\hline $\mathbf{1 1}$ & 164 & 154 & 109 & 247 & 33 \\
\hline $\mathbf{1 2}$ & 191 & 154 & 82 & 302 & 19 \\
\hline $\mathbf{0 4} \mathbf{a} 12$ & 153 & & 302 & 113 \\
\hline
\end{tabular}

Diâmetro em mm; Mín. = valor mínimo; Máx = valor máximo; $\mathrm{n}$ = número de ovotestes. 
380 (Tabela 4), é coerente com o número citado na literatura para B. glabrata: mais de 350 folículos (Paraense, 1975).

Contrariamente a essa variação do número de folículos, o número de divertículos da próstata de B. tenagophila (Tabela 5) não tem variação significativa, enquanto o caramujo cresce de 4 a $12 \mathrm{~mm}$ de diâmetro. Comparando duas espécies, o número de divertículos da próstata de $B$. glabrata de $12 \mathrm{~mm}$ de diâmetro (Tabela 4) é significativamente maior que o de $B$. tenagophila de igual diâmetro $(\mathrm{t}=13,81, \mathrm{p}=0,0)$. Essa estabilidade do número de divertículos e a diferença entre as espécies qualificam esse caráter como diagnóstico específico.

Os valores do teste F de Barlett-Box demonstram homoscedasticidade também nos comprimentos da cauda do ovoteste e da próstata (Tabela 1), cujos parâmetros estatísticos estão nas Tabelas 6 e 7.

Em virtude da heteroscedasticidade revelada no teste de Cochrans ( $\mathrm{C}=0,27$; $\mathrm{P}=0,01)$, foi feita uma transformação nos valores do comprimento da cauda do ovoteste, referentes a conchas de diâmetro variando de 4 a 12 mm de diâmetro. $\mathrm{O}$ LN (comprimento da cauda do ovoteste +1 ), aproxima as variâncias da homogeneidade, segundo o valor dos testes: Cochrans $\mathrm{C}=0,17, \mathrm{P}=$
0,96; Bartlett-Box $\mathrm{F}=0,56, \mathrm{P}=0,79$; variância máxima/variância mínima $=2,06$. Essa transformação é própria para esse tipo de medida, pois inclui valores pequenos e, às vezes, nulos (Zar, 1974), isto é, quando o ovoteste não tem cauda. A análise de variância desses valores transformados é: $\mathrm{F}=6,21, \mathrm{P}=0,00$. A cauda do ovoteste é um caráter que parece crescer independentemente do crescimento do corpo do animal. Embora haja um aumento nos valores das médias dos comprimentos das caudas dos ovotestes, de 0,17 a 1,58 $\mathrm{mm}$, durante o crescimento do animal, valores mínimos iguais a zero ocorrem entre caramujos de $4 \mathrm{~mm}$ de diâmetro de concha (Tabela 6). Além disso, a representação do comprimento da cauda do ovoteste em relação ao diâmetro da concha (Figura 2) mostra uma interseção nos valores mais baixos, sem diferença significativa entre as médias dos comprimentos.

É tentadora a hipótese de que o crescimento da cauda do ovoteste preceda um aumento no número de folículos do ovoteste. Essa explicação é suscitada pela repetida ocorrência de ovotestes sem cauda em alguns caramujos de 4 a $12 \mathrm{~mm}$ de diâmetro. Esses ovotestes sem cauda representariam o final de um ciclo de ampliação do número de folículos, resultado da ocupação do espaço que tinha sido, até então, a cauda do ovoteste. Esta

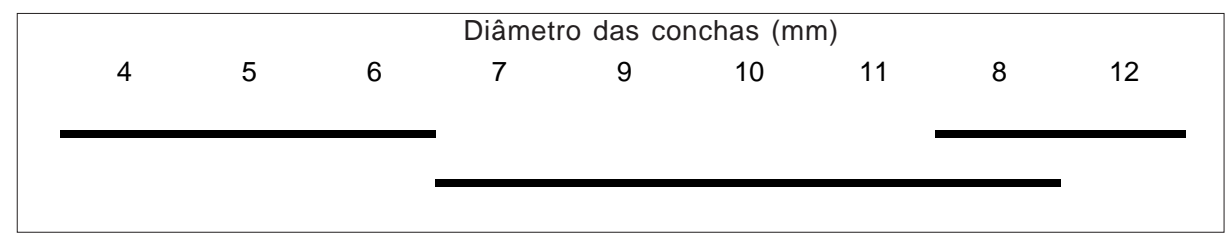

Fig. 1 - Teste Newman-Keuls em nível crítico de significância $(0,05)$ do número de folículos do ovoteste modificado para LN (número de folículos do ovoteste +1 ) de B. tenagophila. Os segmentos incluem diâmetros de conchas de indivíduos cujos números de folículos do ovoteste não diferem significativamente.

TABELA 3

Análise de variância do número de folículos do ovoteste modificado para LN (número de folículos do ovoteste + 1) e de divertículos da próstata durante o crescimento de B. tenagophila de 4 a 12 mm de diâmetro.

\begin{tabular}{|c|c|c|c|c|c|c|c|c|}
\hline \multirow[b]{2}{*}{ Órgão } & \multicolumn{3}{|c|}{ Intergrupos } & \multicolumn{3}{|c|}{ Intragrupos } & \multirow[b]{2}{*}{$\mathbf{F}$} & \multirow[b]{2}{*}{ Prob $\mathbf{P}$} \\
\hline & GL & $\begin{array}{c}\text { Soma dos } \\
\text { quadrados SSQ }\end{array}$ & $\begin{array}{c}\text { Média dos } \\
\text { quadrados } \\
\text { MSSQ }\end{array}$ & GL & $\begin{array}{c}\text { Soma dos } \\
\text { quadrados SSQ }\end{array}$ & $\begin{array}{c}\text { Média dos } \\
\text { quadrados } \\
\text { MSSQ }\end{array}$ & & \\
\hline F. Ot. & 8 & 3,64 & 0,46 & 104 & 3,46 & 0,03 & 13,71 & 0,00 \\
\hline D. Pr. & 8 & 74,05 & 9,26 & 104 & 1257,04 & 12,09 & 0,77 & 0,63 \\
\hline
\end{tabular}

F. Ot. = folículos do ovoteste; $\mathrm{D}$. Pr. $=$ divertículos da próstata; $\mathrm{GL}=$ graus de liberdade; $\mathrm{SSQ}=$ soma dos desvios quadráticos; MSSQ = desvio médio quadrático; Prob = probabilidade. 
interpretação sugestiva, se considerados os caramujos individualmente, é obscurecida pelo exame dos valores médios com as interseções observadas, tanto no número de folículos do ovoteste (Fig. 1) como no comprimento da cauda do ovoteste
(Fig. 2), durante o crescimento dos caramujos. Experimentalmente, foi feita observação de alguns cortes histológicos, com cerca de três micrômetros de espessura, de caudas de ovotestes, sem indício que corroborasse essa hipótese.

TABELA 4

Parâmetros estatísticos do número de folículos do ovoteste e divertículos da próstata de B. tenagophila e $B$. glabrata, de 12 mm de diâmetro de concha.

\begin{tabular}{|c|c|c|c|c|c|c|c|c|}
\hline Espécie & Órgão & Média & D. p. & Moda & Mín. & Máx. & n & Int. conf (0,95) \\
\hline Bt & F.Ot. & 193 & 50 & 178 & 125 & 302 & 18 & 168 a 218 \\
\hline Bg & F.Ot. & 380 & 59 & 338 & 278 & 535 & 44 & 362 a 398 \\
\hline Bt & D.Pr. & 15 & 14 & 4 & 9 & 23 & 19 & 13,0 a 16,9 \\
\hline Bg & D.Pr. & 32 & 4 & 29 & 23 & 43 & 44 & 30 a 33 \\
\hline
\end{tabular}

$\mathrm{Bt}=$ B. tenagophila $; \mathrm{Bg}=$ B. glabrata $; \mathrm{F}$. Ot. = folículos do ovoteste $; \mathrm{D}$. Pr. = divertículos da próstata $; \mathrm{D} . \mathrm{p} .=$ desvio padrão $;$ Mín. $=$ valor mínimo; Máx. = valor máximo; $\mathrm{n}$ = número de caramujos; Int. conf. = intervalo de confiança.

TABELA 5

Parâmetros estatísticos do número de divertículos da próstata em diferentes tamanhos (mm) de B. tenagophila.

\begin{tabular}{|c|c|c|c|c|c|c|c|}
\hline Diâmetro & Média & D. p. & Moda & Mín. & Máx. & n & Int. conf. (0,95) \\
\hline $\mathbf{4}$ & 14 & 3,4 & 10 & 10 & 18 & 06 & 10,2 a 17,4 \\
\hline $\mathbf{5}$ & 14 & 3,5 & 11 & 11 & 20 & 06 & 10,8 a 18,2 \\
\hline $\mathbf{6}$ & 17 & 3,6 & 14 & 13 & 22 & 06 & 12,8 a 20,5 \\
\hline $\mathbf{7}$ & 17 & 3,6 & 16 & 14 & 24 & 06 & 13,1 a 20,6 \\
\hline $\mathbf{8}$ & 17 & 1,8 & 17 & 15 & 20 & 05 & 14,7 a 19,3 \\
\hline $\mathbf{9}$ & 16 & 3,6 & 12 & 11 & 21 & 09 & 12,8 a 18,5 \\
\hline $\mathbf{1 0}$ & 16 & 3,9 & 12 & 11 & 26 & 23 & 14,6 a 18,0 \\
\hline $\mathbf{1 1}$ & 16 & 3,9 & 14 & 09 & 23 & 33 & 15,1 a 17,1 \\
\hline $\mathbf{1 2}$ & 15 & 4,0 & 14 & 09 & 23 & 19 & 13,0 a 16,9 \\
\hline $\mathbf{4 ~ a ~ 1 2}$ & 16 & 3,5 & 14 & 09 & 26 & 113 & 15,2 a 16,5 \\
\hline
\end{tabular}

D.p. = desvio padrão; Mín. = valor mínimo; Máx. = valor máximo; $\mathrm{n}=$ número de caramujos; Int. Conf. = intervalo de confiança.

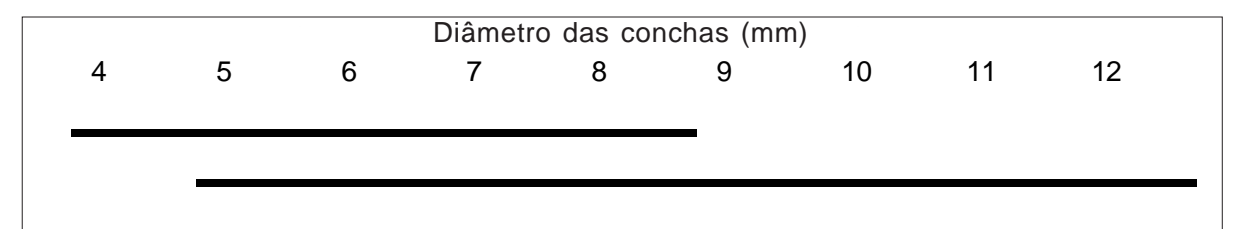

Fig. 2 - Teste de Newman-Keuls em nível crítico de significância $(0,05)$ do comprimento da cauda do ovoteste modificado para LN (comprimento da cauda do ovoteste +1 ) de B. tenagophila. Os segmentos incluem diâmetros de conchas de indivíduos cujos LN não diferem significativamente. 
TABELA 6

Parâmetros estatísticos de medidas $(\mathrm{mm})$ do comprimento da cauda do ovoteste em diferentes tamanhos de B. tenagophila.

\begin{tabular}{|c|c|c|c|c|c|}
\hline Diâmetro & Média & Moda & Mín. & Máx. & n \\
\hline $\mathbf{4}$ & 0,17 & 0,00 & 0,00 & 1,00 & 6 \\
\hline $\mathbf{5}$ & 0,67 & 1,00 & 1,00 & 1,00 & 6 \\
\hline $\mathbf{6}$ & 0,50 & 0,00 & 0,00 & 1,00 & 6 \\
\hline $\mathbf{7}$ & 0,50 & 0,00 & 0,00 & 1,00 & 6 \\
\hline $\mathbf{8}$ & 1,00 & 1,00 & 0,00 & 2,00 & 5 \\
\hline $\mathbf{9}$ & 1,00 & 1,00 & 1,00 & 1,00 & 9 \\
\hline $\mathbf{1 0}$ & 1,22 & 1,00 & 0,00 & 2,00 & 23 \\
\hline $\mathbf{1 1}$ & 1,39 & 1,00 & 0,00 & 4,00 & 33 \\
\hline $\mathbf{1 2}$ & 1,58 & 2,00 & 0,00 & 4,00 & 19 \\
\hline $\mathbf{4} \mathbf{a} \mathbf{1 2}$ & 1,14 & 1,00 & 0,00 & 4,00 & 113 \\
\hline
\end{tabular}

Mín. = valor mínimo; Máx. = valor máximo; $\mathrm{n}$ = número de caramujos

Quanto ao comprimento da próstata, embora o teste $\mathrm{F}$ de Bartlett resulte $\mathrm{F}=1,39$ e $\mathrm{P}=0,20$ (Tabela 1), o teste $\mathrm{C}$ de Cochran $(\mathrm{C}=0,26$ e $\mathrm{P}$ $=0,02)$ e de variância máxima/variância mínima $=5,51$ sugerem a transformação LN (comprimento da próstata +1$)$, que não leva a variâncias mais homogêneas, possivelmente pela natureza das medidas que não têm valores muito baixos, nem zero. Os testes dos valores transformados demonstram: $\mathrm{C}$ de Cochran $=0,25, \mathrm{P}=0,03$; Bartlett-Box F = 1,54, P = 0,14; variância máxima/variância mínima $=6,53$. Conseqüentemente, o comprimento da próstata de caramujos de 4 a $12 \mathrm{~mm}$ de diâmetro foi analisado por teste não paramétrico, Kruskal-Wallis: $\mathrm{N}=113, \mathrm{BC}=76,59$,
$\mathrm{P}=0,00 ; \mathrm{H}_{\mathrm{o}}=$ próstata com mesmo comprimento em caramujos de 4 a 12 mm de diâmetro. Pelo teste das comparações múltiplas (Conover, 1980), verifica-se não haver diferença significativa entre as medidas de comprimento de próstata em caramujos cujos diâmetros de concha variavam de 4 a 6 , ou de 5 a 7 , ou de 6 a $9 \mathrm{~mm}$, isto é, entre os caramujos mais jovens.

Com base nesses resultados de número de divertículos e de comprimento da próstata, podese entender que, durante o crescimento, o investimento feito por $B$. tenagophila na próstata seja de alongamento, mantendo aproximadamente o mesmo número de divertículos. Não foi medido o diâmetro da próstata.

TABELA 7

Parâmetros estatísticos de medidas ( $\mathrm{mm}$ ) do comprimento da próstata em diferentes tamanhos de B. tenagophila.

\begin{tabular}{|c|c|c|c|c|c|}
\hline Diâmetro & Média & Moda & Mín. & Máx. & n \\
\hline $\mathbf{4}$ & 1,50 & 1,00 & 1,00 & 2,00 & 6 \\
\hline $\mathbf{5}$ & 1,83 & 2,00 & 1,00 & 2,00 & 6 \\
\hline $\mathbf{6}$ & 2,17 & 2,00 & 1,00 & 3,00 & 6 \\
\hline $\mathbf{7}$ & 2,83 & 3,00 & 2,00 & 3,00 & 6 \\
\hline $\mathbf{8}$ & 3,20 & 3,00 & 3,00 & 4,00 & 5 \\
\hline $\mathbf{9}$ & 3,11 & 3,00 & 2,00 & 4,00 & 9 \\
\hline $\mathbf{1 0}$ & 3,70 & 4,00 & 2,00 & 5,00 & 23 \\
\hline $\mathbf{1 1}$ & 4,42 & 4,00 & 3,00 & 6,00 & 33 \\
\hline $\mathbf{1 2}$ & 4,84 & 5,00 & 3,00 & 6,00 & 19 \\
\hline $\mathbf{4} \mathbf{a} \mathbf{1 2}$ & 3,69 & 4,00 & 1,00 & 6,00 & 113 \\
\hline
\end{tabular}

Mín. = valor mínimo; Máx. = valor máximo; $\mathrm{n}$ = número de caramujos. 
É razoável supor que o aumento no número de folículos e no comprimento do ovoteste (Tabela 8) seja acompanhado de um aumento de função do órgão. Conseqüentemente, também a próstata deve ampliar sua capacidade de segregar líquido prostático para compatibilizar sua atividade com a do ovoteste. Uma vez que há uma estabilidade no número de divertículos durante o crescimento, é possível que a função prostática se amplie graças a um alongamento do órgão ou a uma maior ramificacão dos divertículos.

Os comprimentos do ovoteste, da glândula mucípara-ootecal e o da bainha do pênis podem ter um tratamento estatístico paramétrico (Tabela 1). A análise de variância (Tabela 8) desses órgãos mostra que houve alteração significativa nos tamanhos dos respectivos órgãos durante o crescimento da concha.

A representação da distribuição do comprimento do ovoteste, em relação ao diâmetro da concha (Fig. 3), mostra continuidade, enquanto o diâmetro da concha mede de 5 a $7 \mathrm{~mm}$ e de 9 a $11 \mathrm{~mm}$. Mas, quando o diâmetro da concha está entre 7 e $9 \mathrm{~mm}$, há uma diferença significativa nos respectivos comprimentos dos ovotestes. O ovoteste cresce em número de folículos (Tabela 3) e em extensão (Tabelas 8 e 9).

$\mathrm{O}$ crescimento da glândula mucípara-ootecal é contínuo, com sobreposições dos tamanhos da glândula, enquanto a concha cresce de 4 a $11 \mathrm{~mm}$ de diâmetro (Fig. 4). Uma vez que a glândula mucípara-ootecal e a próstata estão anatomicamente

TABELA 8

Análise de variância de medidas dos órgãos, durante o crescimento de B. tenagophila, de 4 a 12 mm de diâmetro.

\begin{tabular}{|c|c|c|c|c|c|c|c|c|}
\hline \multirow[b]{2}{*}{ Órgão } & \multicolumn{3}{|c|}{ Intergrupos } & \multicolumn{3}{|c|}{ Intragrupos } & \multirow[b]{2}{*}{$\mathrm{F}$} & \multirow[b]{2}{*}{ Prob $\mathbf{P}$} \\
\hline & GL & $\begin{array}{c}\text { Soma dos } \\
\text { quadrados } \\
\text { SSQ }\end{array}$ & $\begin{array}{c}\text { Média dos } \\
\text { quadrados } \\
\text { MSSQ }\end{array}$ & GL & $\begin{array}{c}\text { Soma dos } \\
\text { quadrados } \\
\text { SSQ }\end{array}$ & $\begin{array}{c}\text { Média dos } \\
\text { quadrados } \\
\text { MSSQ }\end{array}$ & & \\
\hline 1 & 8 & 338,79 & 42,35 & 104 & 112,29 & 1,08 & 39,22 & 0,00 \\
\hline 2 & 8 & 119,86 & 14,98 & 104 & 66,92 & 0,64 & 23,28 & 0,00 \\
\hline 3 & 8 & 20,35 & 2,54 & 104 & 31,96 & 0,31 & 8,28 & 0,00 \\
\hline
\end{tabular}

1 - Comprimento do ovoteste; 2 - comprimento da glândula mucípara-ootecal; 3 - comprimento da bainha do pênis; GL = graus de liberdade; SSQ = soma dos desvios quadráticos; MSSQ = desvio médio quadrático; Prob = probabilidade.

TABELA 9

Parâmetros estatísticos de medidas $(\mathrm{mm})$ do comprimento do ovoteste de $B$. tenagophila, durante o crescimento da concha de 4 a $12 \mathrm{~mm}$ de diâmetro.

\begin{tabular}{|c|c|c|c|c|c|c|c|}
\hline Diâmetro & Média & D. p. & Moda & Mín. & Máx. & n & Int. conf. (.95) \\
\hline $\mathbf{4}$ & 2,00 & 0,63 & 2,00 & 1,00 & 3,00 & 06 & 1,34 a 2,66 \\
\hline $\mathbf{5}$ & 3,33 & 0,52 & 3,00 & 3,00 & 4,00 & 06 & 2,79 a 3,88 \\
\hline $\mathbf{6}$ & 3,67 & 0,82 & 3,00 & 3,00 & 5,00 & 06 & 2,81 a 4,52 \\
\hline $\mathbf{7}$ & 5,00 & 0,89 & 4,00 & 4,00 & 6,00 & 06 & 4,06 a 5,94 \\
\hline $\mathbf{8}$ & 5,00 & 0,71 & 5,00 & 4,00 & 6,00 & 05 & 4,12 a 5,88 \\
\hline $\mathbf{9}$ & 6,33 & 1,12 & 7,00 & 5,00 & 8,00 & 09 & 5,47 a 7,19 \\
\hline $\mathbf{1 0}$ & 6,87 & 0,92 & 6,00 & 5,00 & 8,00 & 23 & 6,47 a 7,27 \\
\hline $\mathbf{1 1}$ & 7,33 & 1,14 & 8,00 & 4,00 & 9,00 & 33 & 6,93 a 7,74 \\
\hline $\mathbf{1 2}$ & 8,26 & 1,28 & 8,00 & 6,00 & 11,00 & 19 & 7,64 a 8,88 \\
\hline $\mathbf{4 ~ a ~ 1 2}$ & 6,40 & 2,01 & 8,00 & 1,00 & 11,00 & 113 & 6,02 a 6,77 \\
\hline
\end{tabular}

D. p. = desvio padrão; Mín. = valor mínimo; Máx. = valor máximo; $\mathrm{n}=$ número de caramujos; Int. conf. = intervalo de confiança. 
justapostas durante o crescimento da concha, era possível esperar que crescessem paralelamente. Entretanto, sendo não-normal a distribuição dos dados do crescimento da próstata e normal a da glândula mucípara-ootecal, diferentes padrões devem atuar no crescimento dos dois órgãos (Tabelas 7 e 10; Fig. 4).

A grande sobreposição dos comprimentos da bainha do pênis, enquanto o caramujo cresce de 4 a $11 \mathrm{~mm}$ de diâmetro de concha, indica a lentidão das mudanças do comprimento do órgão (Fig. 5). A variação entre o tamanho mínimo (1 mm) e o tamanho máximo (4 mm) sugere que, paralelamente, ocorre também um crescimento da concha do menor $(4 \mathrm{~mm})$ ao maior diâmetro $(12 \mathrm{~mm})$, respectivamente (Tabela 11). Realmente, em média, há um crescimento do órgão acompanhando o crescimento de B. tenagophila (Tabela 8). Entretanto, o valor de $1 \mathrm{~mm}$ de comprimento da bainha do pênis ocorre em animais desde 4 até 12 $\mathrm{mm}$ de diâmetro de concha. Isso significa que há caramujos relativamente grandes com bainha do pênis relativamente pequena. Essa variabilidade, que pode ser também de todo o complexo peniano, evoca a possibilidade de seleção ligada ao controle do destino dos espermatozóides transferidos para o parceiro (Eberhard, 1985; Monteiro, 1989).

Em resumo, as análises dos dados referentes aos tamanhos dos órgãos, números de folículos e de divertículos, durante o crescimento da concha de $B$. tenagophila, de 4 a $12 \mathrm{~mm}$ de diâmetro, rejeitam a hipótese nula $(\mathrm{p}=0,00)$, exceto do número de divertículos da próstata $(\mathrm{p}=0,63)$.

É certo que extrapolações de relações entre medida de órgãos e tamanho da concha, além dos valores encontrados na natureza, não têm sentido. Isto é, o tamanho de um órgão de caramujos

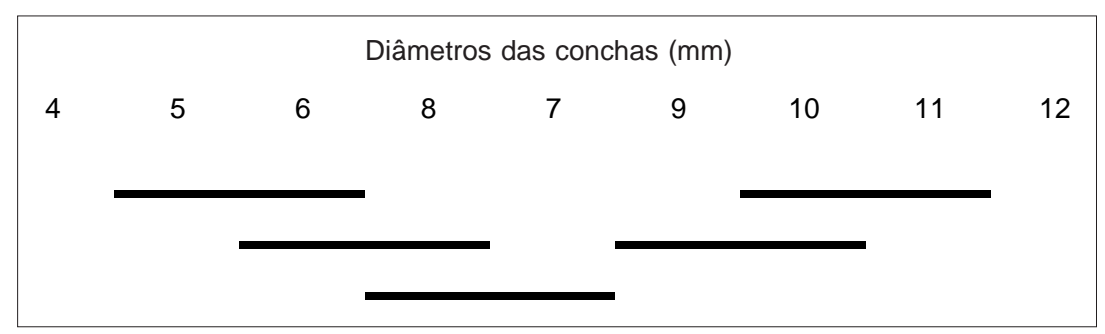

Fig. 3 - Teste de Newman-Keuls em nível crítico de significância (0,05), do comprimento do ovoteste de $B$. tenagophila. Os segmentos incluem diâmetros de conchas de $B$. tenagophila cujos comprimentos do ovoteste não diferem significativamente.

TABELA 10

Parâmetros estatísticos de medidas $(\mathrm{mm})$ do comprimento da glândula mucípara-ootecal de B. tenagophila, durante o crescimento da concha de 4 a 12 mm de diâmetro.

\begin{tabular}{|c|c|c|c|c|c|c|c|}
\hline Diâmetro & Média & D. p. & Moda & Mín. & Máx. & n & Int. conf. (.95) \\
\hline $\mathbf{4}$ & 1,33 & 0,52 & 1,00 & 1,00 & 2,00 & 6 & 0,79 a 1,88 \\
\hline $\mathbf{5}$ & 2,33 & 0,52 & 2,00 & 2,00 & 3,00 & 6 & 1,79 a 2,88 \\
\hline $\mathbf{6}$ & 2,33 & 0,82 & 3,00 & 1,00 & 3,00 & 6 & 1,48 a 3,19 \\
\hline $\mathbf{7}$ & 3,17 & 0,41 & 3,00 & 3,00 & 4,00 & 6 & 2,74 a 3,60 \\
\hline $\mathbf{8}$ & 3,40 & 0,89 & 3,00 & 3,00 & 5,00 & 5 & 2,29 a 4,51 \\
\hline $\mathbf{9}$ & 4,00 & 0,71 & 4,00 & 3,00 & 5,00 & 9 & 3,46 a 4,54 \\
\hline $\mathbf{1 0}$ & 4,35 & 0,78 & 4,00 & 3,00 & 6,00 & 23 & 4,01 a 4,68 \\
\hline $\mathbf{1 1}$ & 4,61 & 0,75 & 5,00 & 3,00 & 7,00 & 33 & 4,34 a 4,87 \\
\hline $\mathbf{1 2}$ & 5,11 & 1,10 & 5,00 & 3,00 & 7,00 & 19 & 4,58 a 5,64 \\
\hline $\mathbf{4} \mathbf{a} \mathbf{1 2}$ & 4,04 & 1,29 & 4,00 & 1,00 & 7,00 & 113 & 3,80 a 4,29 \\
\hline
\end{tabular}

D. p. = desvio padrão; Mín. = valor mínimo; Máx. = valor máximo; $\mathrm{n}=$ número de caramujos; Int. conf. $=$ intervalo de confiança. 
cujas conchas tivessem, supostamente, diâmetro zero ou negativo não tem valor além do especulativo. Não obstante, uma abordagem geométrica pode contribuir para esclarecer o tipo de investimento feito em diferentes órgãos de indivíduos sexualmente maduros. As médias dos tamanhos dos órgãos e dos números de divertículos e de folículos foram relacionados aos respectivos diâmetros de conchas e traçadas retas compensadas, cujas inclinações e interseções permitem inferências sobre os investimentos feitos (Tabela 12).

Os dados da inclinação (Tabela 12) mostram que o número de divertículos da próstata tem o menor valor $(0,12)$ e o número de folículos do ovoteste, o maior $(10,63)$. Isso reforça o argumento de que não haja investimento em produção de divertículos da próstata durante o crescimento de 4 a $12 \mathrm{~mm}$ da concha (Tabelas 1 e 4). A inclinação da reta que se refere ao número de folículos do ovoteste é a maior $(10,63)$, mostrando que, durante o crescimento da concha, há um grande investimento em folículos individuais ou em ramificações de folículos, o que também significa novos folículos e, possivelmente, aumento do diâmetro do ovoteste, que não foi medido neste trabalho. Outra revelação (Tabela 12) é que a inclinação da reta referente ao crescimento do ovoteste é menor do que um $(0,75)$, indicando um modesto investimento em alongamento do órgão. Realmente, o aumento no número de folículos significa aumento no número de unidades produtoras de gametas. No crescimento do ovoteste contabiliza-se também o crescimento da cauda do ovoteste que, por força da metodologia, foi contada dentro do comprimento do ovoteste. Esse acréscimo não deve ter muito significado, uma vez que a inclinação é pequena $(0,16)$. Conforme foi argumentado anteriormente, glândula mucípara-ootecal e próstata

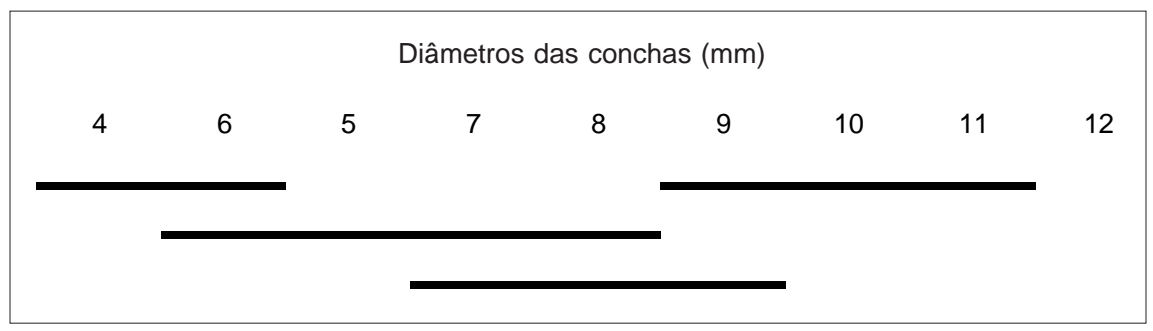

Fig. 4 - Testes de Newman-Keuls em nível crítico de significância $(0,05)$ do comprimento da glândula mucípara-ootecal de B. tenagophila. Os segmentos incluem diâmetros de conchas cujos comprimentos da glândula mucípara-ootecal não diferem significativamente.

TABELA 11

Parâmetros estatísticos do comprimento $(\mathrm{mm})$ da bainha do pênis em diferentes tamanhos de B. tenagophila.

\begin{tabular}{|c|c|c|c|c|c|c|c|}
\hline Diâmetro & Média & D. p. & Moda & Mín. & Máx. & n & Int. conf. (.95) \\
\hline $\mathbf{4}$ & 1,00 & 0,00 & 1,00 & 1,00 & 1,00 & 6 & 1,00 a 1,00 \\
\hline $\mathbf{5}$ & 1,50 & 0,55 & 1,00 & 1,00 & 2,00 & 6 & 0,93 a 2,07 \\
\hline $\mathbf{6}$ & 1,67 & 0,52 & 2,00 & 1,00 & 2,00 & 6 & 1,12 a 2,20 \\
\hline $\mathbf{7}$ & 1,83 & 0,41 & 2,00 & 1,00 & 2,00 & 6 & 1,40 a 2,26 \\
\hline $\mathbf{8}$ & 2,40 & 0,55 & 2,00 & 2,00 & 3,00 & 5 & 1,72 a 3,08 \\
\hline $\mathbf{9}$ & 2,33 & 0,50 & 2,00 & 2,00 & 3,00 & 9 & 1,95 a 2,72 \\
\hline $\mathbf{1 0}$ & 2,30 & 0,64 & 2,00 & 2,00 & 4,00 & 23 & 2,03 a 2,58 \\
\hline $\mathbf{1 1}$ & 2,27 & 0,57 & 2,00 & 1,00 & 3,00 & 33 & 2,07 a 2,48 \\
\hline $\mathbf{1 2}$ & 2,74 & 0,56 & 3,00 & 1,00 & 3,00 & 19 & 2,47 a 3,01 \\
\hline $\mathbf{4 ~ a ~ 1 2}$ & 2,02 & 0,68 & 2,00 & 1,00 & 4,00 & 113 & 2,08 a 2,33 \\
\hline
\end{tabular}

D. p. = desvio padrão; Mín. = valor mínimo; Máx. = valor máximo; $\mathrm{n}$ = número de casos. 
estão anatomicamente justapostas. Portanto, espera-se que o valor do coeficiente de crescimento de seus comprimentos seja bem próximo. A proximidade dos resultados das respectivas inclinações, 0,45 e 0,41, parece compatível com essa previsão.

A inclinação da reta referente à bainha do pênis é pequena $(0,18)$, ou seja, o órgão de $B$. tenagophila cresce pouco em indivíduos sexualmente maduros, provavelmente porque o órgão já esteja suficientemente longo quando entra na maturidade. Talvez esse tamanho esteja ligado ao papel do complexo peniano na determinação dos diferentes caminhos que eles podem tomar dentro do parceiro (Eberhard, 1985; Monteiro, 1989). Um fator contribui para esse argumento.

O comprimento da bainha do pênis é o único, dentre as medidas de extensão, que possui in- terseção com valor positivo (Tabela 12). Isso significa que numa projeção, em sentido especulativo, um caramujo, com diâmetro de concha zero, já teria a bainha do pênis de tamanho um pouco maior que $0,5 \mathrm{~mm}$. Este não seria o caso dos demais órgãos cujas extensões foram medidas. Todos eles teriam comprimento negativo no caso de a concha ter diâmetro zero.

Estes resultados (Tabela 12) demonstram o investimento nos órgãos estudados, enquanto o caramujo cresce. A constância no número de divertículos da próstata pode ser compensada por um aumento da função da próstata, isto é, da produção de líquido prostático, independentemente do tamanho do órgão. Por outro lado, a atividade do ovoteste pode independer do comprimento do órgão e ser proporcional ao número de folículos em ação (Jong-Brink de et al, 1976).

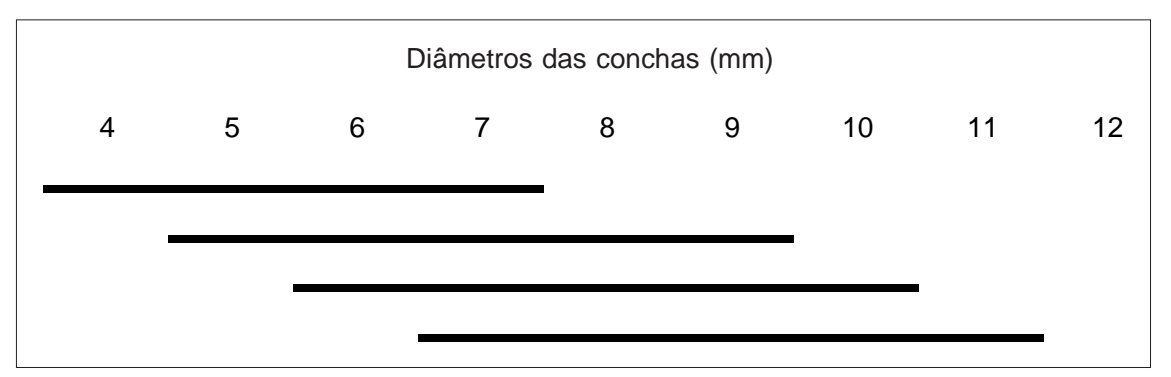

Fig. 5 - Testes de Newman-Keuls em nível crítico de significância $(0,05)$ do comprimento da bainha do pênis de $B$. tenagophila . Os segmentos incluem diâmetros de conchas cujos comprimentos da bainha do pênis não diferem significativamente.

TABELA 12

Parâmetros da reta que relaciona medidas dos órgãos e respectivos diâmetros da concha.

\begin{tabular}{|c|c|c|}
\hline Medida & Inclinação & Interseção \\
\hline $\mathbf{1}$ & 0,16 & $-0,40$ \\
\hline $\mathbf{2}$ & 0,75 & $-0,68$ \\
\hline $\mathbf{3}$ & 10,63 & 53,68 \\
\hline $\mathbf{4}$ & 0,45 & $-0,17$ \\
\hline $\mathbf{5}$ & 0,41 & $-0,20$ \\
\hline $\mathbf{6}$ & 0,12 & 14,78 \\
\hline $\mathbf{7}$ & 0,18 & 0,53 \\
\hline
\end{tabular}

1 - comprimento da cauda do ovoteste (Tabela 6); 2 - comprimento do ovoteste (Tabela 9); 3 - número de folículos do ovoteste (Tabela 2); 4 - comprimento da glândula mucípara-ootecal (Tabela 10); 5 - comprimento da próstata (Tabela 7); 6 - número de divertículos da próstata (Tabela 5); 7 - comprimento da bainha do pênis (Tabela 11). 
A alocação de recursos para o crescimento dos órgãos do aparelho reprodutor, durante a vida da bionfalária, pode estar sujeita a várias influências. A própria natureza do hermafroditismo simultâneo e a economia de recursos para as diferentes funções reprodutivas obedecem a uma programação com bases evolutivas, em que há investimentos fixos criando e mantendo o aparelho reprodutor, mas também há investimento de custo variável, ou seja, produção de gametas. Como o hermafrodita aloca recursos para manter dois aparelhos reprodutores, sua quantidade de energia disponível para a produção de gametas deve ser menor do que aquela que um gonocorista teria para produzir gametas (Heath, 1977). Esta comparação torna quase inevitável a visão de um modelo de alocação de recursos com base em uma Estratégia Evolucionariamente Estável (Charlesworth \& Charlesworth, 1981).

Vários fatores podem atuar no aumento de função do ovoteste durante o crescimento do caramujo. A castração cirúrgica de Australorbis glabratus não afeta a forma ou função dos dutos genitais. A postura de ovos, interrompida na época da cirurgia, pode ser restabelecida após alguns meses. Até mesmo a gônada de castrados púberes pode ser regenerada a partir de um segmento do ovispermiduto. Alterações atribuídas à castração cirúrgica podem se dever à idade do caramujo castrado, isto é, à castração de caramujos que ainda não haviam atingido a maturidade sexual (Vianey-Liaud, 1972, 1979). Em muitos gastrópodes, o crescimento dos órgãos do aparelho reprodutor é dependente das gônadas (Boer \& Joosse, 1975), sendo improvável que as células de Sertoli produzam hormônio (Jong-Brink de, 1977).

Entretanto, o papel do ovoteste aparece no desenvolvimento do aparelho reprodutor de Deroceras reticulatum, um pulmonado hermafrodita, interrompendo, ou tornando lento, o amadurecimento dos dutos de castrados (Runham, 1978). Experimentos com Helisoma duryi, um hermafrodita pulmonado de água doce, acrescentam informações sobre o papel do ovoteste no investimento em crescimento e atividade do aparelho reprodutor. Quando castrado, o crescimento da concha e do corpo aumenta, enquanto diminui a atividade reprodutiva. A glândula do albúmen e a mucípara dos castrados e virgens são maiores do que as dos caramujos que praticam fecundação cruzada. $\mathrm{O}$ oviduto nos castrados é maior do que o nos virgens e nos que praticam fecundação cruzada. O tamanho da próstata permanece inalterado nos castrados, nos virgens e nos que tiveram a glândula corpo dorsal removida (Miksys \& Saleuddin, 1987).

\section{CONCLUSÕES}

A dissecação e medição dos órgãos reprodutores de B. tenagophila foi conseguida, sem aparentes distorções, em solução de sacarose. Os folículos do ovoteste foram individualizados para contagem após a ação de uma solução de RaillietHenry saturada com cloreto de sódio, seguida por passagem em solução de ácido nítrico.

Em B. tenagophila, de 4 a 12 mm de diâmetro, o número de folículos do ovoteste cresce apreciavelmente em caramujos a partir de $6 \mathrm{~mm}$ de diâmetro.

Os números máximos e mínimos encontrados são menores do que os citados na literatura (Paraense, 1975). Já a comparação entre o número de folículos do ovoteste de B. tenagophila e $B$. glabrata sugere que o caráter seja diagnóstico, uma vez que o número em $B$. glabrata é significativamente maior.

O comprimento da próstata varia durante o crescimento do caramujo, embora o número de divertículos não varie significativamente. O número de divertículos da próstata de B. glabrata é maior do que o de B. tenagophila.

$\mathrm{O}$ comprimento da cauda do ovoteste não varia durante o crescimento do caramujo, mas o comprimento do ovoteste aumenta, particularmente quando a concha tem de 8 a 9 mm de diâmetro.

O comprimento da glândula mucípara-ootecal e a bainha do pênis têm um crescimento contínuo enquanto cresce o diâmetro da concha.

Com este estudo fica demonstrado o investimento que a $B$. tenagophila sexualmente madura faz na parte hermafrodita, aumentando o número de folículos e alongando o ovoteste; na parte masculina, alongando a próstata e discretamente a bainha do pênis. Possivelmente aumentando a arborescência dos divertículos da próstata. Na parte feminina, há um aumento no comprimento da glândula mucípara-ootecal.

Agradecimentos — Nossos agradecimentos à Dra. Mara Lúcia Ferreira Dias pelas valiosas sugestões e críticas deste trabalho. À Coordenação de Aperfeiçoamento de Pessoal de Nível Superior (CAPES) - bolsa de estudos. 


\section{REFERÊNCIAS BIBLIOGRÁFICAS}

BARTH, R. \& JANSEN, G., 1959, Contribuição ao estudo da gametogênese dos planorbídeos. 1ª parte: célula nutridora e sua função. Anais da Academia Brasileira de Ciências, 31: 429-55.

BOER, H. H. \& JOOSSE, J., 1975, Endocrinology. In: V. Fretter \& J. Peake, (eds.), Pulmonates, v. 1. New York, Academic Press, pp. 245-307.

CHARLESWORTH, D. \& CHARLESWORTH, B., 1981, Allocation of resources to male and female functions in hermaphrodites. Biological Journal of the Linnean Society, 15: $57-74$.

CONOVER, W. J., 1980, Practical Nonparametric Statistics New York, N.Y., John Wiley \& Sons, Inc., XIV + 493p.

EBERHARD, W. G., 1985, Sexual Selection and Animal Genitalia. Cambridge, Harvard University Press, p. 244.

FISHER, R. A., 1958, The Genetical Theory of Natural Selection. 2 ed., New York, N. Y., Dover Publications, Inc., $291 \mathrm{p}$.

HALLIDAY, T., 1980, Survival in the Wild: Sexual Strategy. Chicago, The University of Chicago Press, p. 158

HEATH, D. J., 1977, Simultaneous hermaphroditism; cost and benefit. Journal of Theorectical Biology, 64: 363-73.

HELLER, J., 1990, Longevity in molluscs. Malacologia, 31: 259-95.

JONG-BRINK de, M., 1977, Spermatogenesis and the role of Sertoli cells in the freshwater snail Biomphalaria glabrata. Cell Tissue Research, 181: 37-58.

JONG-BRINK de, M., WIT de, A., KRAAL G. \& BOER, H H., 1976, A light and electron microscope study on oogenesis in the freshwater pulmonate snail Biomphalaria glabrata. Cell Tissue Research, 171: 195-219.

MIKSYS, S. L. \& SALEUDDIN, A. S. M., 1987, Effects of castration on growth and reproduction of Helisoma duryi (Mollusca: Pulmonata). International Journal of Invertebrate Reproduction and Development, 12: 145-160.
MONTEIRO, W. \& DIAS, B. F. S., 1989, Estratégias reprodutivas em Biomphalaria (Mollusca, Planorbidae). Ciência e Cultura, 41: 1051-4.

NIE, N. H., HULL, C. H., JENKINS, J. G., STEINBRENNER, K. \& BENT, D. H., 1975, SPSS - Statistical package for the social sciences. 2 ed., New York, MacGraw Hill, 675p.

PARAENSE, W. L., 1975, Estado atual da sistemática dos planorbídeos brasileiros. Arquivos do Museu Nacional, Rio de Janeiro, 55: 105-128.

PIANKA, E. R. \& PARKER, W. S., 1975, Age-specific reproductive tactics. The American Naturalist 109: 453-64.

RUNHAM, N. W., 1978, Reproduction and its control in Deroceras reticulatum. Malacologia, 17: 341-350.

SOHN, J. J. \& POLICANSKY, D., 1977, The costs of reproduction in the mayapple Podophyllum peltatum (Berberidaceae). Ecology, 58: 1366-74.

TOMÉ, L. A., 1995, Estudo morfológico do aparelho reprodutor de Biomphalaria tenagophila (Mollusca, Planorbidae). Tese de Doutorado apresentada no Departamento de Biologia/Genética, Instituto de Biociências, USP.

TRIVERS, R. L., 1985, Social Evolution. Menlo Park, California, The Benjamin/Cummings Publishing Company, Inc., 462p.

VIANEY-LIAUD, M., 1972, Étude du contrôle de la maturité des tractus génitaux et de la ponte par castration chirurgicale chez le planorbe Australorbis glabratus Say (Pulmoné Basommatophore). Bulletin de la Societé Zoologique Française, 97: 675-90.

VIANEY-LIAUD, M., 1979, Action de la castration partielle ou totale sur la croissance et le fonctionnement de l' appareil génital chez le planorbe Biomphalaria glabrata (gastéropode pulmoné). Experientia, 35: 188-90.

ZAR, J. H., 1974, Biostatistical Analysis. Englewood Cliffs, N. J. Prentice-Hall, Inc., p. 620. 